\title{
A Study on the Middle Construction in Mandarin Chinese--A Prototype Middle Construction Perspective
}

\author{
Huan Bai \\ Department of Basic Courses, Guangdong Communication Polytechnic, Guangzhou, China \\ Email address: \\ 2267053323@qq.com \\ To cite this article: \\ Huan Bai. A Study on the Middle Construction in Mandarin Chinese--A Prototype Middle Construction Perspective. International Journal of \\ Language and Linguistics. Vol. 9, No. 3, 2021, pp. 62-73. doi: 10.11648/j.ij11.20210903.11
}

Received: March 23, 2021; Accepted: April 15, 2021; Published: May 8, 2021

\begin{abstract}
English middle construction (MC) is one of the most heatedly discussed language phenomenon, however, disagreements and inconsistencies still exist among scholars as for the research scope of the Chinese MC. Based on the prototype elements of English MC, this paper compares the features of those constructions in different scholars' paper and pin down which one is the prototype of Chinese MC and offer an order of their closeness to the prototype. Findings and explanations are demonstrated as follows: firstly, under the framework of prototype theory, it is argued that MC has its own prototype. The author assumes" the bread slices smoothly" as the English prototype for the high frequency of being cited at discussing the related topics of MC in literature. The prototypical properties of prototype elements are presented below: (1) implicit agent; (2) active in form; (3) simple present tense; (4) patient subject; (5) primary responsibility of subject; (6) adverb and experiencer sub-role of agent; (7) the aspect of the middle verb is either activity or accomplishment verb; (8) general modality reading; (9) causative and affected subject. Secondly, a closer look at Chinese MC is conducted, which reveals that different scholars have different ideas on what kind of construction is Chinese MC. Taking the prototype elements of prototypical English middle construction as criterion, the author compares the constructions in those scholars' paper with them and finds out that they share different number of features. Construction in Yu \&Si's paper and parts of construction in Cao's paper are regarded as typical Chinese MC because they share all the prototype elements of prototypical English MC. Their closeness to the prototype depends on the number of similarities they have in common. The author ranks these constructions from the most typical member to the worst member in the following order: Yu \&Si, He, Chen, Ding, Cao, and GU. They structure around the prototype and exhibit graded centrality to the prototype. Thirdly, this paper also explains why the same construction can be classified into different grammatical categories, to be more specific, why the construction in Ding's paper is regarded as notional-passives and construction in Chen's paper is classified into the grammatical category of tough construction. According to prototype theory, category has fuzzy boundaries and a category may merge with neighboring category, therefore, MC merges with notional-passives and tough construction for they have overlapping areas.
\end{abstract}

Keywords: English Middle Construction, Mandarin Chinese Middle Construction, Prototype Theory, Prototype Features

\section{Introduction}

Since Keyser and Roeper (1984) [1] put their first finger in English MC, it has become one of the most heated topics in linguistic filed. Such kinds of constructions are labeled by Keyser and Roeper (1984) as middle constructions like: This car drives easily, which can be characterized as "NP+VP+AP". $\mathrm{MC}$ is a special type of construction which is abundant in West-Germanic languages and Romance language. The existence of $\mathrm{MC}$ as a type of construction across languages is not denied. Research of $\mathrm{MC}$ in languages other than
Indo-European language is necessary in order to prove the claim of the universality of MC. Chinese scholars have conducted relative research on $\mathrm{MC}$ in Mandarin Chinese. However, disagreements on the scope of Chinese MC exist. Therefore, the major purpose of this paper is to explain this phenomenon from a cognitive language perspective. It tries to find out which construction can be regarded as typical Chinese $\mathrm{MC}$ and rank the constructions in those scholars' paper in the order of typicality of Chinese MC. The author puts the different language peculiarities aside for the moment and assumes that all MC in different languages should be a 
grammatical category which has its prototype effect. Prototype elements of prototypical English MC are pinned down and are used as the criterion in comparison.

\section{Literature Review}

Fruitful findings have been achieved in the research of MC in Indo-European languages, especially in English. For those who are familiar with Chomsky's UG (universal grammar) theory, it is very natural for them to wonder whether there is corresponding $\mathrm{MC}$ in Chinese. If there is, it can put weight on the claim of the universality of MC. Sung is the first linguist who mentioned MC in Chinese. [2] Since then, many scholars conducted research on Chinese MC. However, disagreements exist. Ding [3] argues that Chinese MC is a construction where a patient argument does not occur in the typical object position but instead in the grammatical subject position and crucially the middle verb is not inflection-ally marked as a passive verb. However, other scholars classify such construction in the grammatical category of notional-passives. The typical examples of such construction are listed as follows: 衣服洗好 了。敌人打退了。障碍排除了。Cao [4] proposes that middle construction in Chinese has the structure of "NP+VP (V 起来/ 上去/着) +AP”. It will be proved later that this is a heterogeneous structure. He [5] argues that there are atypical $\mathrm{MC}$ in Chinese. He has made a systematic comparative study between them. As for the atypical MC, it differ from typical $\mathrm{MC}$ because their theta-role of the subject is different. The subject of the latter is patient while the subject of the former is adjunct, namely, non-argument. Comparisons of the features of these atypical Chinese MC with prototype elements of prototypical English MC will be made to check whether this is the only difference between them. Instances of his atypical Chinese MC are listed below: 食堂吃起来方便。数码相机照 起来方便。幻灯片演示起来直观。 $\mathrm{Gu}$ [6] holds that typical Chinese MC should have the structure of "NP (patient) $+\mathrm{Adj}+\mathrm{V}$ ", and he claims that a construction including derivation adjectives, such as “可 V/V 人” or “难 V/好 V” is typical Chinese MC, for instance:自然灾害真可怕。腐败现 象真气人。这个面包很好吃。他的嗓音很难. Yu \&Si [7] claim that “ $\mathrm{NP}+\mathrm{V}$ 起来 (predicate) $+\mathrm{AP}$ (complement)" is the real Chinese MC. They divide the structure into three sub-groups. The typical instances of this construction are listed as follows: 这本书读起来很容易。这个活干起来很难。 Chen [8] lists different examples as typical Chinese MC which can be referred to linguistic structures with such a configuration:" NP+好/容易/难/难以+V”, like 剧本不容易 写。这个字难写。这本书好卖. Just like construction in Ding's paper, constructions in Chen's paper also have the dubious status of being members of MC because others label it as tough construction.

It can be seen that scholars differ greatly concerning $\mathrm{MC}$ in Chinese. Each of them use their own construction as typical Chinese MC, which will lead to different findings. The major aim of this paper is to find out which construction can be regarded as typical Chinese middle construction and rank them in the order of typicality of Chinese MC.

\section{Theoretical Framework: Prototype Categorization Theory}

\subsection{Modern Theory of Categorization: The Prototype Theory}

Wittgenstein [9] proposes the famous family resemblance theory based on his investigation of the semantic category of the word "spiel" (game) in his book Philosophical Investigation. He believes that the instances of games are linked to one another by" family resemblance", just as some members of the family may share the same build, others the same gait, and others the same eye color. All members of the family do not necessarily share any common characteristics in common.

Rosch and Mervis gave an abstraction version of family resemblance:" a set of items of the form $\mathrm{AB}, \mathrm{BC}, \mathrm{CD}, \mathrm{DE}$, that is, each item has at least one, and probably several elements in common with one or more items, but no, or few elements are common to all items." [10]

\subsection{Definitions of Prototype}

There are actually two different ways to understand prototype. The first one holds that a prototype is the best or most typical example of a category or the cluster of the central members or the best example of a category, sharing the maximum number of features with instances of other categories. [11]. It is basically a matter of looking at the relationship between a category and its members. The second one involves attempting to describe a category or concept in terms of its characteristic features. It holds that a prototype is an abstract thing and not simply an example. It demonstrates itself as a set or cluster of prototypical features. [12] A prototype is defined as a set of abstract characteristic properties and we just compare real items with these properties. For instance, the prototype of bird might be a kind of average bird with the abstract properties of a bird (i.e., small, with wings, feathers, the ability to fly, etc.), but it cannot be particular species of any real individual. Actually, the two properties of prototype are compatible with each other. If the prototype in a category is regarded as the best example, which has full membership of the category must have most of the prototypical features. Therefore, the two perspectives have much in common in the essence. In this paper, either perspectives will be adopted in dealing with the prototype of $\mathrm{MC}$.

\subsection{Characteristics of Prototype Theory}

Firstly, category is not structured in terms of shared necessary and sufficient features, instead, it is structured by a crisscrossing network of similarities and structured in terms of their best examples. Prototype categories exhibit a family resemblance structure. A family resemblance relationship takes the form $\mathrm{AB}, \mathrm{BC}, \mathrm{CD}, \mathrm{DE}$, that is, each item has at least one, and probably several elements in common with one or more items, but no, or few elements are common to all item. 
Secondly, members in the same category have different degrees of typicality, in another word, not every member is equally representative for a category. Whether an entity belongs to a category or not depends on its similarities to the prototype. The more similarities it has, the closer it is to the prototype and thus the more central its status within the category. According to Croft and Cruse [13], not all members of a category have the same status within the category. People have intuitions that some category members are better examples of the category than others. Members that are judged to be the best examples of the category can be considered to be the most central in the category. There are good members which have more properties in common with other members of the category and bad members (also called marginal members) which have less properties in common with other members of that category while have more properties of other categories.

Thirdly, the boundaries of the prototypical categories are blurred. Cognitive categories take a radial chain structure with fuzzy boundaries and exhibit nature of openness and extroversion. Categories have their own clear centers (prototype), however, the boundaries between categories are not so clear-cut because in marginal areas they may overlap. With the fuzzy nature of categories in mind, it is easy to explain why some people classify tomato into the category of fruit while others list it into vegetable.

\section{Prototype Elements of English MC}

\subsection{Assuming “The Bread Slices Smoothly" as the Prototype of English MC}

The reasons for assuming "the bread slices smoothly" as English MC are given below. Firstly, a prototype can be the best or most typical example of a category, and it is the most representative of things in class. $\mathrm{MC}$ as a definable grammatical category, although there is not an agreement on the defining feature, some particular examples are frequently mentioned in their papers. Therefore, there should be the best example as its prototype. Secondly, members of a category achieve prototypical status, for we encounter them much more frequently. Frequency is an important factor and source of prototype. In other words, a prototype can be pinned down by the frequency of being cited. This paper applies the prototype theory to English MC and draws the prototype from the frequency of being cited." The bread slices smoothly" has been frequently cited when talking about related topics. Thirdly, linguists take "the bread slices smoothly" as a middle construction for granted. Although they have not reached an agreement on the definition of MC, all of them accept that "the bread slices smoothly" is a MC. Therefore, "the bread slices smoothly" is assumed as prototype. The following sections will elaborate on its syntactic and semantic features, or prototype properties.

\subsection{Implicit Agent}

There is an implicit agent which cannot be realized overtly syntactically. Most of the native English speaker have the intuition that there is a covert agent. Besides, scholars have given evidence to prove that the middle verb is a transitive verb from the lexical level. Although there are opposite views which hold that middle verb is an intransitive verb. In this paper, the author is inclined to follow the first view which takes the verb in middle construction as a transitive verb. Therefore, the transitive verb should include two participants, patient and agent. The following examples can prove that agent cannot be overtly expressed in English MC.

a*The bread slices smoothly by John.

b*This door opens easily by Sue.

c*This metal rod bends easily by a very weak person.

Keyser \& Roe per proposed that all-by-itself test could imply the existence of the agent in the logical level of MC. They held that ergative could appear with" all-by-itself" while $\mathrm{MC}$ cannot. It suggests that $\mathrm{MC}$ has an implicit agent but ergative do not. The following examples can illustrate this.

a. The boat sank all by itself.

$b^{*}$ These books sell easily all by themselves.

c* The bread slices smoothly all by itself.

Other scholars use phrases such as "with no/little/a little/some/ a lot of effort" and "with / without difficulty" to prove the existence of implicit agent because "effort is energy expended by an agent", for example,

(3) a. This floor waxes with no effort.

b. This poetry translates with no effort.

\subsection{Active in Form}

The verb is in active morphology which is similar to active construction but differs from passive construction. Contrary to active construction, the subject of $\mathrm{MC}$ is not an active participant of the event (agent), but a passive one (patient) which makes it close to passive construction as far as meaning is concerned. The agent is absent and no passive morphology is used. As many scholars have pointed out, the MC is a hybrid of active morphology and passive subject. Compare " the bread slices smoothly" with the active and passive sentences:

(4) a. The bread slices smoothly. (Middle construction)

b. Somebody slices the bread smoothly. (Active sentence)

c. The bread is sliced smoothly. (Passive sentence)

Morphological speaking, the verb" slice" in the MC is active in form, just like the verb in active sentence. However, the subject of MC" the bread" is not the agent like the one in active sentence, but the patient of the sentence like the passive sentence. Compared with the passive sentence, the MC has the same patient "the bread" as their subject, however, their predicates have different verb form. Besides, there is another different property between them, the subject of the passive can be adjoined in the "by-phrase", but he subject of middles cannot be adjoined in "by-phrase".

(5) a.* The bread slices easily by John.

b. The bread is sliced easily by John.

Linguist Halliday [14] divides the voice system into three types in English: active voice, passive voice and middle voice. The middle voice is the one between active one and passive 
one, which morphological likes the active voice while semantically likes the passive one. Therefore, sentence in (5a) is middle voice. Middle voice is unmarked voice as the active voice, which has no structure of its own, and the predicate verb is in active verb form.

\subsection{Simple Present Tense}

The explicit feature of MC is that they are in present tense. Sentences with other tenses are regarded as odd or unacceptable.

(6) a. Our cooker cleans easily. No detergent. A gentle wipe will do.

b. The door opens easily.

c. Five minutes ago, the car drove easily, according to the mechanic.

d. The book was selling easily at eight' clock yesterday morning because the author was there.

e. Bureaucrats have bribed easily.

f. Bureaucrats have been bribing easily.

\subsection{Patient Subject}

The subject of MC serves the theta-role of patient. The middle verb has the argument structure (agent, patient). As what has been mentioned above, agent cannot be expressed overtly. The subject of the construction is the patient which should be in the object position after the transitive verb. In another word, while the patient is moved to the subject position. For example, the subject of the sentence "the bread slices smoothly" is not the agent but the patient because "bread" is the object of the verb "slice". The element in the subject position is called patient subject.

\subsection{The Primary Responsibility of Subject}

The primary responsibility of the subject was first noticed by Van Oosten [15] who believes that it is certain properties of the subject that make the proposition as a whole true. Therefore, if the bread slices easily, it is due to the inherent characteristics of the bread rather than due to any other participants of the event. This is one of the important differences between MC and passive construction. The subject of the passive does not convey any responsibility; sometimes it even conveys a sense of helplessness. MC are different from passive construction because the subject of the middle construction is represented as having certain inherent properties which prompt, hamper, or ever prevent the realization of the idea expressed by the predicate. Therefore, the participant that is to be chosen as middle subject should bear the following features: (the properties of) $\mathrm{X}$ cause the $\mathrm{V}$-ing (of $\mathrm{X}$ ) to be Adj. That is to say, some (inherent or designing) properties of the grammatical subject in MC cause the event to occur in the manner denoted by the adverbial, for instance:

(7) The book sells easily.

(The inherent property of) the book causes the selling of the book to be easy.)

Another evidence for the primary responsibility of the subject can be provided through the restrictions on the types of reason clauses in middle construction. For instance,

(8) a. The frozen meat cuts easily because it is not deep frozen.

b. ${ }^{*}$ The frozen meat cut easily because the chef is very skillful.

c.* The frozen meat cut easily because the knife is very sharp.

d. To sum up. The patient at the subject position has some inherent characteristics which take the primary responsibility of making the proposition as a whole true.

\subsection{Adverb and the Experiencer Sub-role of the Agent}

Adverb is an indispensable element of prototypical English $\mathrm{MC}$ and it usually gives the agent an experiencer sub-role. For example, 9 (a) and (b) are ungrammatical if the adverbs are absent.

(9) $a^{*}$ The magazine reads.

b* The bread slices.

Only facility adverbs and event adverbs are permitted. The facility adverbials are those that can point out he manner of the action, like "easily, rapidly, with great difficulty" and event adverbials are the ones describing or modifying the course of the event. Middle adverbs expresses the outcome of the interaction between the implicit agent and patient, therefore, the manner adverbs, which refer to the manner of a specific agent in performing the task rather than the interaction between the patient and any agent in general, are not permitted.

\subsection{The Aspect of the Middle Verb Is Either Activity or Accomplishment Verb}

The aspect of the middle verb is either activity or accomplishment verb. Vendler [16] divides verbs into four classes: activity, accomplishment, achievement and state which can be demonstrated in the following table.

Table 1. Classification of Verbs.

\begin{tabular}{lll}
\hline classes & Criterion & Examples \\
\hline State & No time scale & Know, have, believe... \\
Achievement & Time scale, inherent end point, does not hold intermediate stages & Recognize, find, win... \\
Activity & Time scale, no inherent end point & Run, walk, push... \\
Accomplishment & Time scale, inherent end point and holds of intermediate stages & Build, write, sell... \\
\hline
\end{tabular}

At the lexical level, most of the middle verbs are accomplishment verbs which hold over definite stretches of time and they have endpoint which is a change of state. From the table we can see that state verbs and activity verbs are similar because they denote state of affairs or actions that are on-going in time and have no inherent endpoint. On the other 
hand, accomplishment verbs and achievement verbs are telic which denote actions that have natural endpoint. State verbs differ from verb of other classes because they denote non-dynamic, i.e., stative states of affairs that don't have an internal temporal structure. Activity verbs, accomplishment verbs and achievement verbs, on the other hand, denote dynamic processes or actions that can be organized along a time scale. The action denoted by an activity verb holds for an unspecified number of stages on the time scale but does not include a specific endpoint. The action denoted by an accomplishment verb, on the other hand, includes an endpoint as well as the stages leading up to it. Finally, the action denoted by an achievement verb is instantaneous. In other words, there are no intermediate stages and the only thing of importance is the end point of the action. The accomplishment and activity verbs are eligible for $\mathrm{MC}$, however, state and achievement verbs are excluded. The following sentences are examples to prove that only activity and accomplishment verbs are eligible:

(10) a. The car drives easily. (activity verb)

b. This book reads easily. (accomplishment verb)

c. ${ }^{*}$ French acquires easily. (achievement verb)

d. $*$ The answer knows easily. (state verb)

\subsection{General Modal Reading}

Many linguists have discovered this feature. However, they have different opinions concerning the interpretations. For example, Condoravdi proposes that it is quantification over events, as in habitual which generalize over event, how things are usually or habitually done. For example, he always carries an umbrella with him when he goes out. Habitual middles are sentences like" the newspaper reads daily". On the contrary, Fagan and Fellbaum argue that it is quantification over agent. Fellbaum remarks:" what is perceived to be generic or non-eventive about middles is not always the action itself. Rather, it is expression that any potential agent can perform, or could have performed, the action with the result, or in the manner indicated. Thus, it is not the action, but the agent that is non-specific or generic. They can be interpreted in the following two ways respectively: one is any instance of the act is performed in such a manner denoted by the adverb of the middles and the other is any instance of the agent (or, people in general) can perform the act in such a manner denoted by the adverb of the middles. For example, the sentences "the bread slices smoothly" can have two interpretations. One is "any act of slicing the bread is performed smoothly, the other is "anyone (or, people in general) can slice bread smoothly." In this paper, either way will be adopted because both are reasonable and don't conflict with each other.

\subsection{Causative and Affected Subject}

Middle verb should be causative verb which causes change of state of patient subject. As for the construction" the bread slices smoothly", the bread changes its state from being a whole one to being sliced into pieces. With many verbs, the agent causes a change of state in patient--the patient is affected.
Middle predicates are commonly postulated to be of this type and this is indeed the case for MC formed from the verbs such as cut, break, open. With this in mind, explain the following phenomenon.

(11) a. These rocks break/ cut/shatter/smash easily.

b. ${ }^{*}$ These rocks destroy/eliminate/annihilate/obliterate/ruin easily.

Levin remarked:"... the break verbs describe specifics of the resulting physical state of an entity (e.g., whether something is broken, splintered, cracked, and so on) rather than simply describing the fact that it is totally destroyed." Greenspon believes that nothing more can be said about the resultant state of a destroying event, so the destroy verbs are not causative verbs. Besides, he regards the result state as one of the defining characteristics of causative verbs. "Hit" and "kick" cannot form middles because it is difficult for us to see that their patients are affected. But they can form middles if they are combined with resultant particles. In such case, their meanings affected patients, for instance,

(12) a. Arnold kicked the door. b. * Plywood doors kick easily. c. Arnold kicked the door in/open.

d. Plywood doors kick in/open easily.

\section{Middle Construction in Mandarin Chinese}

Detailed analysis will be conducted on the different constructions in different scholars' paper. Each section will be proceeded in the following manner. First, each scholar's view on which construction should be real Chinese MC will be briefly presented. Then the author will compare the properties of the construction with the prototype elements of English MC. Finally, the author will use the prototype theory to find out which construction can be regarded as prototype of Chinese $\mathrm{MC}$ and rank them in the order of typicality based on the features they share in common with the prototype elements.

\subsection{Cao's Account}

Cao proposed that Chinese $\mathrm{MC}$ bears the structure "NP+VP+AP", NP stands for noun or noun phrases, VP stands for verb phrase, including $\mathrm{V}$ 起来/来/上去/着. AP stands for adjective phrase which describe state. She further analyzes these elements in detail, that is to say, she elaborates on NP, VP and AP respectively. As for the initial noun phrase, she argues that it is noun that serves as subject, however, subjects of these sentences are not noun, not to mention being patient, for instance:

(13) a. 刮脸, 这么看起来, 不光是一种习惯, 里面还含 着些情韵呢。

b.和著名作家同台领奖, 说起来多么令人羡慕。

c. 那么, 多给老人们尽心, 而少生点兄弟妯娌间的闲气,

算起来还倒真不错呢。

d.关于王升，可就说起来没完了。

e.酒色上了她的脸, 使她看上去有几分柔媚。

The subjects of the above sentences which are regarded as 
middle construction in Mandarin Chinese in Cao's paper are quite different and varied. However, for the prototypical English MC, the subject is noun which generally serves as the patient. The subject of 13 (a) is a verb, although from the semantic point these verbs are designated rather than assertion. Just as Cao proved, these verbs can be replaced with "what" rather than "how", for instance:

(14) a. 刮脸, 这么看起来, 不光是一种习惯, 里面还含 着些情韵呢。

b.什么看起来, 不光是一种习惯, 里面还含着些情韵呢。 呢。

c. *怎么么看起来, 不光是一种习惯, 里面还含着些情韵

The issue of lexical categories in Chinese has little morphology has long been the focus of a lot of discussion. Nevertheless, in this paper the author believes that the category of the subject still belongs to verb, at least they are not typical noun. As for others, the subjects are also not noun or noun phrases, instead, they are prepositional phrase or empty category which recoverable from the previous clause. From the above sentences, it is easy to jump to the conclusion from the surface that they are not MC because they are quite different from the prototypical English MC with which we are familiar. Putting the intuition aside, the author will have a rational analysis in the following paragraphs.

As for the verb phrase, she proposes that it is "V+起来/上 去/着”. In the “V+起来” structure, they can be further divided into two types in terms of movement. In one type, the "V+起 来” cannot be put before the subject noun, while in other type, such kind of movement is allowed. Besides, they can also be classified into two types according to whether the "V+起来" can be deleted. If "V+起来" can be moved before the subject, they can also be deleted. On the other hand, if "V+起来" cannot be moved before the subject, they cannot be deleted either, for instance:

a 那种脚手架安装起来很麻烦。

$\mathrm{b} *$ 安装起来那种脚手架很麻烦。

$\mathrm{c} *$ 那种脚手架【】很麻烦。

$\mathrm{d}$ 他们算起来都四十几岁的人了。

$\mathrm{e}$ 算起来他们都四十几岁的人了。

$\mathrm{f}$ 他们【】都是四十几岁的人了。

The author will compare the features of the first type of MC in which "V+起来” cannot be deleted and cannot be moved before the subject with the prototype elements of English MC. Firstly, it is active in form but passive in meaning. The author proposes that the insertion of “被” or “被-phrase" to test whether they are active or passive. The following sentences are customarily regarded as passives because the insertion of “被” or “被-phrase” produced acceptable construction. For instance:

a 衣服洗好了。

b 衣服被洗好了。

In contrast, no such insertion is allowed in this construction. (17) * 那种脚手架被安装起来很麻烦。

Secondly, the predicate “安装” has the argument structure (agent, patient). The subject 脚手架 is patient. The agent is syntactically realized, while the patient is moved to the subject position.
Thirdly, it is also in simple present tense which implies that it is the inherent property of 脚手架 which has nothing to do with time. In Chinese, time-bounded event often employ aspect marker like 着, 了, 过, 在, for instance:

$\mathrm{a}$ 他来的时候我正在吃饭。

$\mathrm{b}$ 我在吃饭。

$\mathrm{c}$ 我吃完饭, 你吃了吗?

$\mathrm{d}$ 我吃过了, 他正忙着呢。

e 墙上挂着一面钟。

However, the presence of these aspect marker, either before or after or right in the position of 起来, result in ungrammatical constructions.

$a^{*}$ 这种脚手架安装着/了/过/起来很难。(before 起来)

$\mathrm{b}$ *这种脚手架安装起来着/了/过/很难。( after 起来)

$\mathrm{c}^{*}$ 这种脚手架着/了/过/很难。(in the position of 起来)

Nor can other temporal or frequency adverbs be used before the verb, for instance:

(19) *这种脚手架正将已经安装起来很容易。

These restrictions show that this type of construction uses simple present tense to attribute properties to subject that hold regardless of time.

Fourthly, the verb is lexical telic and is an accomplishment verb as far as its aspect is concerned. Telic words denote actions that have a natural endpoint. The word 安装 belongs to accomplishment verb because it includes the endpoint as well as the stages leading up to it.

Fifthly, regarding causative and affected subject, it includes three temporal components. The first one is the causative phase over which the agent begins to assemble. The second one is the interval phase in which 脚手架 is assembled in difficult manner. The third one is the result phase in which it is in a new state, that is, 脚手架被安装好. In another word, the subject 脚手架 is affected.

Sixth, the subject is responsible for the realization of the truth value of the whole sentence. It is the inherent property of such kind of scaffold (maybe the structure of scaffold is too complicated) that makes people assemble it in a difficult way.

Seventh, the construction also includes an indispensable adverb and it gives the agent the experience $r$ sub-role. Experience $r$ is the entity who is aware of the action or state described by the predicate but which is not in the control of the action or stage. To be more specific, the agent experiences the difficulty when he assembles the scaffold 。

Eighth, there is general modal reading. Here the author chooses the causative modality to interpret the above sentence.

(20) a 那种脚手架安装起来很麻烦。

$\mathrm{b}$ 那种脚手架由于结构复杂等原因使得安装非常麻烦。

The generic interpretation means the MC predicates an inherent characteristic property of the subject of the middle verb which determines the progress of the event denoted by the verb. That is to say, MC express that any act denoted by the verb is done in the manner specified by the adverb. As for the above sentence, it can have the following generic interpretation.

a 那种脚手架安装起来很麻烦。

b. Whenever there is an act of assembling scaffold, the 
assembling is troublesome.

Then a brief analysis of the second type will be conducted. The sentence will be rewritten as follows:

$\mathrm{a}$ 他们算起来都是四十几岁的人了。

$\mathrm{b}$ 算起来他们都是四十几岁的人了。

$\mathrm{c}$ 他们【】都是四十几岁的人了。

Firstly, the subject is noun, but it is not a patient. Dowty proposed the contributing properties for the agent and patient respectively. The contributing properties for the patient are as follows:(1) undergoes change of state (2) incremental theme (3) causally affected by another participant (4) stationary relative to movement or another participant (5) does not exist independently of the event, or not at all. In the first sentence, the subject “他们” does not have the above five properties of the patient proposed by Dowty, so it is not a patient of the predicate verb “算”. Secondly, it does not have the obligatory adverb, instead, it is a noun, that is,四十几岁的人. Thirdly, there is no causative, that is to say, there is no three phases and the subject is not affected. Fourthly, they are active in form because the insertion of “被” or “被-phrase" produced unacceptable construction.

(23) *他们被算起来都是四十几岁的人了。

Fifthly, it uses simple present tense. If the aspect marker “着, 了, 过, 在” is inserted into the sentence, it will be ungrammatical. Sixth, the predicate verb "算” is a two place predicate, so the external argument is not syntactically realized. The implicit agent is people in general. Seventh, the subject is responsible for the truth value of the whole sentence. Eighth, it has no general modal reading. Ninth, the aspect of the middle verb is an activity verb.

Therefore, from the above analysis, we may come to the conclusion that the second type of middle construction, to be more specific, it is the structure "NP (patient) +V 起来+AP" in which $\mathrm{V}$ 起来 cannot be deleted and cannot be moved before the subject that conform to almost all the prototype elements of English MC.

\subsection{Ding's Account}

Ding takes the term "MC" to describe a construction where a patient argument does not occur in the typical object position but instead in the grammatical subject position and crucially the middle verb is not inflection-ally marked as a passive verb. $\mathrm{He}$ argues that Chinese has construction syntactically and semantically comparable to $\mathrm{MC}$ in other languages. This construction is a sentence type having a patient argument in the sentence initial position but lacking an explicit passive marker" bei", which is also called notional passives by other scholars. The following sentences are examples cited from his paper.

$\mathrm{a}$ 衣服洗好了。

$\mathrm{b}$ 敌人打退了。

c. 障碍排除了。

Firstly, they are passive in form and meaning. The insertion of "bei" or "bei-phrase" can be used to test whether a sentence is active or passive. As far as the above sentence are concerned, the insertion of "bei" produced acceptable construction. Besides, they can be embedded into a "ba" construction, as is shown below:

$\mathrm{a}$ 衣服洗好了。衣服被洗好了。

$\mathrm{b}$ 敌人打退了。敌人被打退了。

c 障碍排除了。障碍被排除了。

$\mathrm{d}$ 把衣服洗好了。

e 把敌人打退了。

f把障碍排除了。

Secondly, the subjects of these constructions are all patients. The predicate in the above sentence are all two-place predicate which have two arguments, that is, the agent and the patient. The agents are invisible syntactically, but as a native speaker, the lexical semantics tells us that there must be an underlying subject or agent. Thirdly, these constructions do not employ simple present tense. They use present perfect tense and past tense because in the above sentences, there are aspect marker “了”. Fourthly, the middle verb are all activity verb rather than stative verb because they do not denote any inherent endpoint. Fifth, they do not have general modal reading. The examples in Ding's paper do not have such kind of modal reading. For example, 衣服洗好了。It is equal to the passive sentence in meaning, that is 衣服被洗好了. But it is difficult to paraphrase into sentences like*衣服能够被洗好了。Such a sentence is ungrammatical from the intuition of a native Chinese speaker. Besides, they do not have generic reading, that is to say, their understood subject cannot be any people, and instead, it must be some particular person who performs the act of washing the clothes or removing the barriers. Sixth, the subjects of these constructions are affected as the middle verbs cause a change of state of the subject. Greenspon regards the result state as the defining characteristic of causative verbs. Seventh, in the above constructions, the truth value of the proposition has nothing to do with the subjects. The successful outcome of the action due entirely to particular agent. For instance,衣服洗好了. It is the agent who performs the action of washing that makes the whole sentence true, and it is irrelevant to the properties of clothes. Eighth, the last feature we compare with is the obligatory element adverb. Although some of the constructions have adverbs, they are quite different from the adverbs in propositional English MC, which are generally facility adverb or event adverb. What's more, these adverbs do not give the agent an experiencer sub-role.

\subsection{GU's Account}

$\mathrm{Gu}$ proposes that the Chinese $\mathrm{MC}$ includes derivation adjectives, such as “可 V/V 人，好 V/ 难 V". The following sentences are cited from his paper.

a 自然灾害真可怕。

$\mathrm{b}$ 没想到这儿的景色这么迷人。

c 这个面包很好吃。

$\mathrm{d}$ 他的嗓音很难听。

He also gives his reasons. Firstly, the hidden verb of the predicate is transitive verb. For “可 V/V 人”, the verb has the argument structure (experiencer, causer); for “好 V/ 难 V”, the verb has the argument structure (agent, patient). Secondly, these constructions are active in form but are passive in meaning. Fourthly, these constructions all describe certain 
properties of the subject.

His analysis seems plausible, however, it seems very difficult for native Chinese speaker to associate these constructions with English MC. Our traditional analysis of these constructions is "subject (noun) + predicate (adj)". The constructions in Gu's paper are quite different from prototypical English middle construction. The major difference is that adjective serves as the predicate of the sentence. If that is the real case, there is no common ground between them. It is argued that prototype elements of English MC presuppose that the argument structure of the predicate verb is [agent, patient]. If there is no predicate verb, there is no need to mention whether it is active or passive because only verbs have the active form or the passive form, neither do we need to examine its tense or aspect of the middle verb. If there is no verb, there is neither general modal reading nor causative because the subjects are not affected at all. There is no adverb in these constructions. The two constructions have only one thing in common, that is, the subject is responsible for the truth value of the whole sentence. In a word, the construction in Ding's paper don't share any feature in common with those of prototype elements in English middle construction except for the primary responsibility of the subject.

The author does not think there is any verb in these constructions, though Gu points out that there is a hidden verb in the adjective predicate. As modern Mandarin Chinese, “可 $\mathrm{V} / \mathrm{V}$ 人，好 V/ 难 V" are all generally accepted as adjectives. As native Chinese speaker, few of us know how it is originally formed. These phrases are used as adjectives. In his paper, there are many such adjectives, for instance, the type of “可 V": 可爱, 可悲, 可贵, 可耻, 可怜, 可笑, 可疑; the type of “V 人”: 动人, 感人, 惊人, 诱人, 宜人... the type of “好 $\mathrm{V}$ ": 好吃, 好看, 好听, 好办, 好走...; the type of “难 V": 难过, 难受, 难忘, 难看... Those are all adjectives used to describe the state or the property of the subject. Put in the sentence, they serve as predicate. It is unique language phenomenon of Mandarin Chinese.

In a word, as these types of constructions use adjectives as predicate, and this is quite different from the English MC that use verbs as predicate, so there are no comparable points between these two distinctive types of constructions.

\subsection{Yu \& SI's Account}

Yu \& Si first proposed that not all “NP+V 起来 + AP" belong to Chinese MC. According to the semantic orientation of AP, they divide such construction into 3 sub-classes. The first class is the one in which AP modifies the initial subject, for instance: 这本书看起来不错。这个活干起来很脏。The second class in the one in which AP modifies the implicit agent, for instance, 这本书读起来很轻松。这个活干起来很吃力。The third class is the one in which AP modifies the verb, for instance:这本书读起来很容易。这个活干起来很难。In their opinion, “V 起来” in the first class can be deleted without affecting its original meaning, so the "V 起来" serves as adjunct while AP serves as the predicate. In English MC, it is the verb that serves as predicate, so the first class should be excluded. As far as the author is concerned, she agrees with them on this point as pointed out in the above analysis on Cao's argument, this type of construction dose not conform to most of prototype elements of English MC. However, they should not be excluded from the Chinese MC. Under the prototype theory, this type of construction is only marginal member. As for the second class, they believe that the underlying subject of the verb is not an agent but an experiencer, so they are not qualified to be MC. Under the prototype theory, the members in a category are not involved with a matter of "either... or...", but a question of degree, therefore, this type of construction is also a bad member of the category of MC. Finally, they proved that only the third type is the typical Chinese MC. What is immediately relevant to this paper is to judge whether the third type construction conforms to all types of the prototype elements of English MC. The third type can be summarized in an abstract form: NP (subject) +V 起来(predicate) $+\mathrm{AP}$ (complement). The author will use the former two sentences as examples, which can be rewritten as follows:

a 这本书读起来很容易。

b 这个活干起来很难。

Comparisons between this construction and the prototype elements of English MC will be conducted. Firstly, they are active in form. Both constructions will be ungrammatical if "bei" is inserted into the sentence. Besides, in both constructions, 起来 cannot be embedded into "ba" construction. Secondly, our knowledge of lexical semantics tells us that the act denoted by the verb involves another entity, namely, the person who performs the act. In another word, the verbs in those two sentences are two-place predicate. However, only one argument is syntactically present which is in the subject position. Besides, the subject is the direct internal argument of the verb, namely, the patient or theme. The external argument, namely, the agent, is not syntactically realized. However, as native speaker, we can perceive that these sentences must imply an agent. Thirdly. Both sentences are in simple present tense. The presence of the aspect markers (着/了/过/在), either before or after or right in the position of 起来 result in ungrammatical constructions. Nor can other temporal or frequency adverbs be used before the verb. It uses simple present tense to attribute properties to subject regardless of time. Fourthly, it is generally accepted that subject is responsible for the occurrence of the action denoted by the middle predicate. For instance, 这本书读起来很容易. We can say it is the inherent property of the book that is responsible for the reading process to be easy. (i.e.: it is simple in content, few new words, the language is plain, and there are many illustrations and pictures and so on.) Besides, the requirement on the rational clause after this construction also indicates the responsibility of the subject.

(27) a 这本书读起来很容易因为它内容简单, 生动有趣。 $\mathrm{b}$ *这本书读起来很容易因为它知识渊博。

Fifth, the predicate verb 读 and 干 are both activity verbs because they have no inherent endpoints. Sixth, there are adverbs. Without the adverb, the resulted sentence will be ungrammatical. Seventh, the patient is affected. Take the second sentence for example, we can say that after the agent's 
hard labor, the job has changed from its initial form to the final state. Eighth, these constructions have general modal reading. Take the construction “这本书读起来很容易” as an example. It has the following generic interpretations: whenever there is an act of reading this book, the process of reading is easy. Finally, it also involves the causative modal interpretation: the inherent property of the book causes reading of it to be easy. To sum up, this construction have all the properties in common with the properties of prototypical English MC.

\subsection{He's Account}

He claims that there are atypical MC in both English and Chinese. The only difference between typical middle construction and atypical middle construction is that their theta-role of the subject is different. The middle verb of the former one has the argument structure of (agent, patient), that is to say their subject is patient. However, the subject of the atypical MC is not internal argument of the verb (patient), instead, it is the adjunct, namely, non-argument. Adjunct is an optional constituent typically used to specify, e.g. the time, location, or manner in which an event takes place. Our task here is to find out whether it is only theta-role of the subject that distinguish the two types of middle construction. The thematic roles such as location, instrument, manner, and goal and so on are eligible for middle subjects, for instance:

$\mathrm{a}$ 食堂吃起来方便。(Location)

b 第一排听起来清楚。(Location)

c 飞利浦剃须刀剃起来舒服。(Instrument)

$\mathrm{d}$ 数码相机照起来方便。(Instrument)

$\mathrm{e}$ 短信联系起来方便。(Means)

f幻灯片演示起来直观。(Means)

Firstly, they are all active in form. If the "bei" is inserted into those sentences, they will become unacceptable. Besides, these constructions cannot be embedded in "ba" construction. Secondly, there is an underlying agent but are syntactically invisible. It is obvious that the predicate verb in the above sentences involves another entity, namely the agent who performs the act. “吃, 听, 剃, 照, 联系, 演示” are all three-place predicate. There are internal argument of these verbs which is called theme or patient and external argument which is called agent. In this case, not only the agent is syntactically invisible but also the patient is absent, however, we can infer what the patient is from the verb. The subjects of these sentences serve as adjuncts, namely, non-argument. For instance, “食堂” and“第一排”serve the theta-role of its predicate as location.“飞利浦剃须刀” and“数码相机”serve as instrument.“短信” and“幻灯片” serve as means. Thirdly, these verbs all belong to accomplishment verb because they have time scale, inherent endpoint and hold of intermediate stages. Fourthly, they all use simple present tense. The presence of the aspect marker (着/了/过/在) will result in ungrammatical construction. Nor can other temporal or frequency adverbs be used before the verb. It uses simple present tense to attribute properties to subjects that hold regardless of time. Fifth, there is no causative reading. As the subject is not patient, there is no state of change. These adjuncts remain what they originally are because they are used to specify the time, location or manner in which an event takes place and it is impossible for these participants to be affected. Sixth, there is an obligatory adverb in the construction and adverb gives the agent the experiencer sub-role. For example, when eating in the canteen, the agent experiences convenience. Seventh, the subject is also responsible for the truth value of the whole proposition. For example, eating in the canteen entails you needn't go out to buy food and make dinner by yourself, and you also need not wash the dishes after the meal; there is a lot of food for you to choose. It is because of these that we can say it is convenient to eat in the canteen. Eighth, there is modal reading. Those sentences can have the following modal reading.

$\mathrm{a}$ 告诉公路开起来很畅快。

$\mathrm{b}$ 任何人都可以在高速公路上很畅快地开车。

c 派克笔写起字来很流畅。

$\mathrm{d}$ 任何人都可以用派克笔很流畅地写字。

\subsection{Chen's Account}

In Chen's paper, he put forward his own account on what is the real Chinese MC. He lists the following examples as typical Chinese MC.

$\mathrm{a}$ 剧本不容易写。

$\mathrm{b}$ 这个字难写。

c 这本书好卖。

$\mathrm{d}$ 那些半大孩子还不好蒙。

Unlike other scholar's MC, this construction is different from English MC at the surface level. English MC generally has the configuration of "NP+VP+AP", while this construction's structure is "NP+AP+VP". However, whether the "难” and “好” belong to the word category of adverb is still a controversial issue. It seems that only a limited number of words can appear in the position of AP, namely, 难, 难以, 容易, 好. Firstly, the verb is transitive. The verb is two-place predicate. Its internal argument is in the subject position and its thematic-role is patient. The agent is implicit and like MC in English, by-phrase is not allowed in this construction. Secondly, they all employ simple present tense which indicates that it is the inherent property of the subject which has nothing to do with time. The insertion of any aspect marker will result in ungrammatical construction. Thirdly, the subject is responsible for the action expressed by the predicate because of its inherent properties. For instance, it may due to the many strokes of the character that makes it difficult for people to write it. Besides, the requirement on the rational clause after the construction also indicate the responsibility of the subject, for instance:

a 小孩很容易骗因为他们容易轻信别人。

b*小孩很容易骗因为他非常狡猾。

Fourthly, there is no causative reading, which means that the patient subject is not affected. Fifthly, there is invariably an adverb in this construction, though the adverbs are limited. These adverbs also give the agent a sense of ease or difficulty in performing an act. Sixth, there is also generic reading and modality reading of the construction. The author can paraphrase the above sentences into the following one:

(31) 这个问题容易解决。 
Whenever there is an act of solving the problem, the process will be easy. (Generic interpretation)

(The inherent property of) the problem cause the solving of it to be easy. (Causative modality)

Eighth, they are active in form. The insertion of "bei" cause these constructions unacceptable. Besides, they cannot be embedded in "ba" construction.

\subsection{Summary and Analysis}

After comparing the different types of constructions in different scholars' papers in terms of prototype elements of English MC, the author draws a table to demonstrate their differences and similarities in a clear and systematic way. Under the theoretical framework of prototype theory, this paper have reached the following findings.

Table 2. Comparisons between prototype elements of English middle construction with constructions in all the six scholars'paper.

\begin{tabular}{|c|c|c|c|c|c|c|}
\hline The prototype elements of English middle construction & Cao & Ding & Gu & Yu \&Si & $\mathrm{He}$ & Chen \\
\hline 1 active morphology & + & - & - & + & + & + \\
\hline 2 patient-subject & $+/-$ & + & - & + & - & + \\
\hline 3 simple present tense & $+/-$ & - & - & + & + & + \\
\hline 4 aspect of middle verb (activity or accomplishment) & $+/-$ & + & - & + & + & + \\
\hline 5 implicit agent & + & + & - & + & + & + \\
\hline 6 general modal reading & $+/-$ & - & - & + & + & + \\
\hline 7. causative & $+/-$ & + & - & + & - & - \\
\hline 9. Adverb and the experiencer sub-role assigned to the subject & $+/-$ & - & - & + & + & + \\
\hline
\end{tabular}

Firstly, the prototype Chinese MC is confirmed. According to prototype theory, a prototype is the best or most typical example of a category or the cluster of central members or best examples of a category, sharing the maximum number of features or attributes with other instances in its category. In another word, a prototype should have most of the prototypical features. Yu \& Si's construction and one type of construction in Cao's paper have all the prototype elements of English MC, so they are regarded as the best example of Chinese MC. Construction in Yu \& Si's paper are "NP (subject) $+\mathrm{V}$ 起来 (predicate) +AP (complement)" and that in Cao's paper is “NP+V 起来+AP”, in which “V 起来” cannot be deleted and cannot be moved before the subject. As a matter of fact, they are the same in essence. They just use different methods to narrow the scope of "NP+V 起来+AP". The instances of such kind of construction can be listed as follows:

(32) a 这种脚手架安装起来很麻烦。

$\mathrm{b}$ 这本书读起来很容易。

c 这个活干起来很难。

Secondly, a radical chain is drawn to demonstrate the structure of the Chinese MC with the best example at the center of the circle and the less typical ones are organized around the circle. According to the prototype theory, members in the same category have different degrees of typicality. (Figure 1) Not all members have equal status. The prototype is the best example of the category and it is at the center of the circle. Other members' closeness to prototype depends on their similarities to it. The most similarities it has, the closer it is to the prototype and thus the more central its status within the category. Through the above analysis and comparison, the author found that constructions in Yu \&Si's paper, that is "NPpatient (subject+V 起来(predicate) +AP (complement)" together with one type of construction in Cao's paper $(\mathrm{NP}+\mathrm{V}$ 起来+AP) in which V 起来 cannot be deleted and cannot be moved before the subject) are typical Chinese MC because they have all the features of prototype elements of English MC. Therefore, they can be the prototype of Chinese MC, thus they are at the center of the radical chain. Construction in Chen's paper share eight features in common with the prototype of English MC, therefore, they are closest to the Chinese prototype MC. Construction in He's paper have only two different properties with prototype elements of English MC, so they are a little far from the typical Chinese MC. Construction in Ding's paper share four features in common with the prototype element, so they are not good members of MC. Besides, they are classified into the category of notional passives by others. Therefore, they are in the overlapping area between the two categories. Construction in GU's paper and other type of construction in Cao's paper share one or two features in common with the prototype elements. They are the worst members of $\mathrm{MC}$ and it is very difficult for people to recognize these constructions as $\mathrm{MC}$, therefore, they are farthest from the prototype and are at the boundary area of the category of MC. Though it is difficult for people to accept their status of being in the category of MC, they are still regarded as MC because they still show a certain degree of relation to prototype of $\mathrm{MC}$. In other words, they are organized around prototype.

Thirdly, the reasons why some constructions have dubious status can be explained as follows. According to prototype theory, the category has fuzzy boundaries. Some members of a category might have unclear or ambiguous status with respect to one or more categories. Those members are regarded as marginal members. They might be half way in this and half way in that or they might be on the border line between two categories. It is very clear that constructions in Chen's paper share eight properties with prototype elements and it is actually closest to the prototype of Chinese MC. The fact that it is labeled as tough construction by others can be explained as follows: it is a good member of MC but a bad member of tough construction because it shares the maximum number of features with other instances MC. As for construction in Ding's paper, it shares four features with prototype elements of MC, therefore, it is safe to conclude that it is a bad member of middle construction and notional passives. In another word, it is in the overlapping area between the two categories. The 
boundaries between categories are not so clear-cut. That is why the same construction can be classified into two different categories. A category may merge with neighboring category.
To some extent, conclusions can be drawn that middle construction merge with tough construction and notional passives.

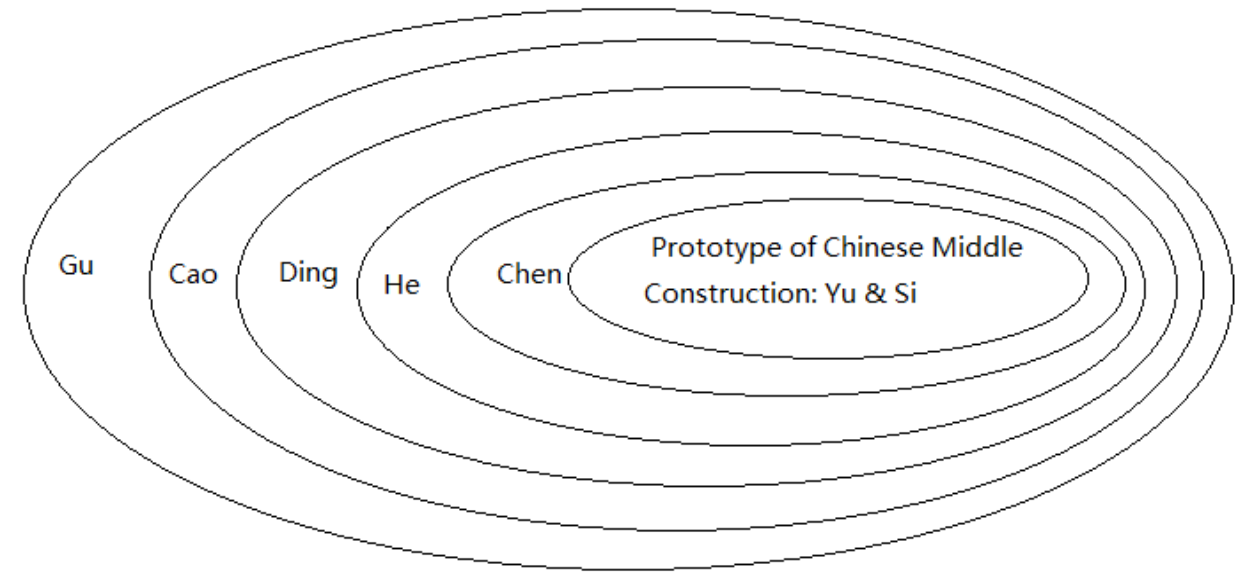

Figure 1. The structure of the category of Chinese middle construction.

Fourthly, explanations of why different scholars use different defining features to define the MC are elaborated. Prototype categories is flexible, that is to say, one can extend them in different kinds of ways. And this is useful because they are able to accommodate new experiences and a changing world. According to Taylor, categories can be redefined and restructured or highlight certain aspects of categories through the use of so-called hedges, i.e., real, par excellence, technically speaking, strictly speaking, sort of, kind of, so-called, in that, etc. Prototype categories are the categories we operate with and we can actually modify them. For instance:" he is a friend of mine, in that $i$ have known him for years, but we don't really have much in common." What the speaker doing then is taking the word" friend" or whatever the definition of a friend is. The speaker then gives the reason why this person is categorized as friend: $i$ have known him for years, so the length of time you have known somebody then becomes the criterion for saying he is a friend, but another possible criterion for being a friend is excluded. So "in that" is a hedge that is used actually to redefine and re-weight the features of the category. That explains why different scholars use different defining features to define real MC in both English and Chinese. Some scholars take the presence of an implicit agent as the defining feature while other scholars take the modality as the defining feature. Choice of defining feature of MC depending on people's emphasis on a certain aspect of it.

\section{Conclusions}

\subsection{Major Findings}

This paper tries to take cognitive perspective on MC and makes some improvements on the findings of previous research. The major findings of the paper are listed as follows:

Firstly, the author conducted a more comprehensive research on the prototype elements of English MC, adding more elements to it. The author assumes" the bread slices smoothly" as the prototypical English MC and proposed nine prototype elements, which are demonstrated below:(1) there is an implicit agent; (2) active in form; (3) simple present tense; (4) patient subject; (5) the primary responsibility of the subject; (6) adverb and the experiencer sub-role of the agent; (7) the aspect of the middle verb is either activity or accomplishment verb; (8) general modal reading; (9) causative and affected subject.

Secondly, the author uses prototype elements of English $\mathrm{MC}$ as the criterion to compare the different constructions in different scholars' paper. The detailed point-to-point comparisons are conducted. It shows that some of the constructions bear more features of prototypical English MC than others. As constructions in Si \& Yu's paper and parts of constructions in Cao's paper share all the features of prototypical English MC, they are regarded as prototype of Chinese MC.

Thirdly, as for other constructions in other scholars' paper, the author ranks them in the order of closeness to prototype according to the number of features they share with the prototype elements of English MC. The order of these middle constructions from the best one to the worst one are listed below: Yu \&Si, Chen, He, Ding, Cao, Gu. They structured around the prototype and exhibit graded centrality to the prototype of Chinese MC.

Fourthly, explanations on the dubious status of some members of Chinese MC are provided. Categories have fuzzy boundaries. A category may merge with neighboring category and they share some overlapping area. That explains why constructions in Chen's paper are labeled as MC by some scholars while they are classified into the category of tough construction by others. The same holds true to explain why constructions in Ding's paper are regarded as MC while viewed as notional passives by others.

\subsection{Limitations}

Firstly, English and Chinese belong to different language 
systems and they have their own language peculiarities. In this paper, the universality of all the languages is assumed while the language peculiarities are ignored. Therefore, the ignorance of the difference between the two languages has limited the perfection of the study and the findings of this study can only be a tentative one.

Secondly, the present study points out which construction is prototype of Chinese MC. The comparison between Chinese and English MC is based on the properties of English middle construction. This paper focuses on the common ground between them, leaving out the differences. Further research can be carried out on the peculiar properties of Chinese MC. A contrastive analysis between them will bring a whole picture to MC in English and Mandarin Chinese.

\section{Acknowledgements}

Supported by "General project of Foreign Language Teaching Directing Committee of Vocational Colleges of the Ministry of education in 2019. (Project no: FLEC037)", "General project of Information Technology Teaching Directing Committee of the Ministry of Education in 2018 (project no: 2018LXB0300)" and "Key Project of Guangdong Foreign Language Teaching Directing Committee in 2018 (project no: 201805)".

\section{References}

[1] Keyser, S, J \& Roeper, T. On the middle and ergative constructions in English [J]. Linguistic Inquiry, 1984 (15): 381-416.

[2] Sung, K, M. Chinese Middle and the Affectedness Condition, [C], paper presented at the first international conference on Chinese Linguistics, Singapore, 1992.

[3] Ting Ren. The Middle Construction in Mandarin Chinese and the Syntactic Approach. [C]. Paper presented at the $15^{\text {th }}$ North America Conference on Chinese Linguists at Michigan State University. 2003.
[4] Hong Cao. On the Relationship between the Hierarchical Structure and Grammar of Middle Constructions [J]. Language Teaching and Research. 2004 (5): 42-52.

[5] Wen-zhong He. Definition of Middle Construction. [J]. Foreign Language Education. 2005 (4): 9-14.

[6] Chuan-yu Gu. Middle voice Sentence Patterns in Modern Chinese--Syntactic and Lexical Realization of Voice Transformation. Chinese Journal 2005 (2), 22-32+95.

[7] Guang-wu Yu \& Hui-wen Si. The Definition of Chinese Middle Construction--Concurrent Research on Differentiation of $\mathrm{NP}+\mathrm{V}$-qilai+AP Structures. Studies in Language and Linguistics. 2008 (1): 69-78.

[8] Liming Chen. Comments on middle construction in Cao's paper.

http://www.pkucn.com/viewthread.php?action=printable\&tid= 168457. 2006.

[9] Wittgenstein, L. Philosophical Investigation.[M] Oxford: Basil Blackwell, 1983.

[10] Rosch, E \& Mervis, C, B. Family Resemblance: studies in the internal structure of categories [J]. Cognitive Psychology, 1975 (7): $573-605$.

[11] Taylor, J. R. Linguistic Categorization: prototypes in Linguistic Theory [M]. Oxford: Clarendon Press: 1995.

[12] Brown. C. H. A Survey of Category types in Natural Language in Meaning and Prototype [M] Savas L. Tsohatzidis. Routledge: 1989.

[13] Croft, W \& Cruse. D. Cognitive Linguistics [M]. Cambridge University Press. 2004.

[14] Halliday, M, A, K. An Introduction to Functional Grammar [M]. London, Edward Arnold, 1985.

[15] Van Oosten, J. 1977. Subjects and agent hood in English [A]. In Beach, W., S. Fox \& S. Philosophy. Papers from the Thirteenth Regional Meeting of the Chicago Linguistic Society [C]. Chicago: Chicago Linguistics Society. 459-471.

[16] Vendler, Z. Adverbs pf Action, CLS20, part 2 [C]. Papers from the Para session on Lexical Semantics. 1984. 